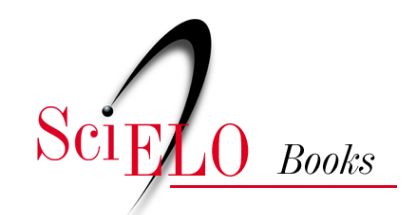

3. O território da perspectiva jurídico-institucional e jurídicourbanística

\title{
A face do tecido urbano e as mazelas ao acesso à moradia social: como o caso do município de Petrópolis desvenda a construção de uma lenda urbana
}

\author{
Carmem Matos
}

\section{SciELO Books / SciELO Livros / SciELO Libros}

MATOS, C. A face do tecido urbano e as mazelas ao acesso à moradia social: como o caso do município de Petrópolis desvenda a construção de uma lenda urbana. In: PENALVA, A., CORREIA, A.F., MARAFON, G.J., and SANT'ANNA, M.J.G., eds. Rio de Janeiro: uma abordagem dialógica sobre o território fluminense [online]. Rio de Janeiro: EdUERJ, 2018, pp. 254-280. ISBN 978-857511-476-6. https://doi.org/10.7476/9788575115169.0011.

All the contents of this work, except where otherwise noted, is licensed under a Creative Commons Attribution 4.0 International license.

Todo o conteúdo deste trabalho, exceto quando houver ressalva, é publicado sob a licença Creative Commons Atribição $\underline{4.0}$.

Todo el contenido de esta obra, excepto donde se indique lo contrario, está bajo licencia de la licencia Creative Commons $\underline{\text { Reconocimento } 4.0 .}$. 


\section{A face do tecido urbano e as mazelas ao acesso à moradia social: como o caso do município de Petrópolis desvenda a construção de uma lenda urbana}

Carmem Matos

\section{Introduçáo}

O Estatuto da Cidade (Lei n. ${ }^{\circ}$ I0.257/OI), ao estabelecer seus princípios e diretrizes, identifica a cidade como um bem coletivo e aponta que os vários aspectos do exercício do direito de propriedade (domínio, apropriação, uso do solo e disposição) só são legítimos quando cumprem com a sua função social. Logo, cidade, coletividade e função social entrelaçam-se mutuamente formando um bem coletivo abrangente constituído por serviços públicos, infraestrutura, moradia, relaçóes sociais e econômicas, que existe, principalmente, para acolher pessoas.

A cidade, portanto, resulta da produção e interação desses bens materiais, e imateriais, conferindo um espaço multifuncional muito valorizado por seus moradores, que, por sua vez, anseiam em usufruir desse dinamismo de forma igualitária e justa. Sendo assim, o uso do solo urbano deve vincular-se a uma regulação que resista à possibilidade de tratar a terra como uma mercadoria, já que desta depende o direito à moradia, base fundamental da dignidade humana e direito social expresso na Constituição Federal.

De acordo com a Constituição e o Estatuto da Cidade, o imóvel que não cumpre a sua função social é aquele ocioso em razão de subutilização ou não utilização/edificação. Portanto, torna-se necessário definir critérios para a identificação da ociosidade, determinando se um imóvel está ou não inserido na função social da cidade.

A gestão do território urbano, portanto, deve pautar-se no controle do uso da terra em benefício de toda a coletividade, visando incluir uma grande parcela da população de baixa renda que não consegue aceder às áreas servidas de 
melhor infraestrutura urbana. Esse controle é possível a partir do manejo coerente e articulado dos instrumentos urbanísticos disponíveis, valorizando, por exemplo, a aplicação do IPTU progressivo no tempo e a arrecadação de imóvel por abandono do proprietário.

Neste capítulo, trataremos da importância do cadastro imobiliário não ser visto apenas para fins de arrecadação tributária, mas como instrumento essencial ao conhecimento e planejamento do território urbano. Trata-se de uma condição preliminar à atuação das prefeituras na política habitacional, possibilitando a identificação dos imóveis que não estejam cumprindo sua função social.

Esclarece-se, por oportuno, que a gestão do território, nesse estudo, está focalizada no planejamento do direito à moradia a partir de um mapeamento completo do tecido urbano com o objetivo de oferecer soluçôes viáveis à diminuição do déficit habitacional. A construção de um cadastro com base de dados ampla e diversificada permite que o planejamento habitacional seja integrado ao conhecimento do território e, com isso, as áreas centrais, mais valorizadas em razão de sua infraestrutura e de seus serviços essenciais, seriam aproveitadas pela produção de habitação social, favorecendo às camadas mais vulneráveis da população que alcançariam moradia em locais dotados com melhores equipamentos públicos.

Tal mapeamento, além de integrar o conhecimento territorial ao planejamento habitacional, pode promover alternativas de planejamento urbano mais adequadas à realidade local, uma vez que identifica espaços pertinentes a toda a dinâmica social, oferecendo um contexto mais rico e diversificado a partir do estudo da cidade.

Essa dinâmica personalizada permite romper o formato único de produção de habitação social estabelecido pelo Programa Minha, Casa Minha Vida (PMCMV), baseado na construção de grandes condomínios nas periferias das cidades nos moldes do antigo $\mathrm{BNH}$.

O mapeamento do tecido urbano torna-se um instrumento necessário ao enfrentamento do déficit habitacional, uma vez que instrumentaliza novas alternativas em contraponto à opção imposta pelo mercado imobiliário. Esse instrumento de planejamento urbano, ao ser manejado, contribui com a possibilidade de o poder municipal resgatar a planificação habitacional às suas máos, retirando do mercado a exclusividade de atuação. Essa retomada de poder leva a um controle do uso do solo mais vinculado ao interesse social do 
que ao lucro de mercado, rompendo com a mercantilização da terra urbana e planejando o seu uso a partir do próprio potencial.

O poder público, ao omitir-se em relação ao planejamento do tecido urbano, deixa-o ao arbítrio das construtoras que atuam no mercado imobiliário. Essa inversão de funçóes levou o mercado a tratar a produção de moradia social como um grande nicho de mercado, e, por consequência, as empresas do ramo passaram a protagonizar a política habitacional por meio do PMCMV, controlando a sua produção, a terra urbana, o financiamento e quem se beneficia dele (Schimbo, 20Io).

Entretanto, a responsabilidade pela política urbana é do município, ainda que a União formule e financie a política habitacional (Bonduki, 2009). Sendo assim, mesmo aderindo ao PMCMV, cabe ao poder municipal atuar de acordo com sua competência. Isso significa que deve protagonizar o planejamento habitacional atuando em diversas frentes, como, por exemplo, indicando imóveis aptos à produção de moradia em áreas mais centrais e infraestruturadas, elaborando projetos adaptados às condiçôes do seu território em contraponto àqueles de cunho mercantil e formato padrão, e envolvendo as comunidades nas escolhas e discussóes a fim de desenvolver um planejamento legítimo e coerente com o interesse local.

A legitimidade de planejamento perpassa pela identificação de imóveis ociosos ou subutilizados como fonte de potencial fundiário fundamental na construção da política de moradia social. Esses representam elementos frequentes no tecido urbano, que muitas vezes servem como instrumento de especulação imobiliária, ou, simplesmente, retratam bens destituídos de função social, portanto, não aproveitados pelo planejamento urbano.

Nesse sentido, se é do município a responsabilidade pela política urbana, a ele cabe instrumentalizar a política de habitação com o conhecimento do seu território, incluindo, nessa perspectiva, os imóveis ociosos que o compóem.

Neste estudo, procuramos explorar essa possibilidade por meio de um estudo de caso, tomando o município de Petrópolis, no estado do Rio de Janeiro, como referência. $\mathrm{O}$ texto está composto desta introdução como a primeiro parte. Na segunda, traçamos um breve perfil do município de Petrópolis, destacando a sua normativa em relação à política habitacional. Na terceira, apresentamos um estudo de caso onde foram levantados os imóveis ociosos em três bairros do primeiro distrito, a área central do município. Finalmente, na quarta parte, apresentamos algumas considerações à guisa de conclusão. 


\section{Cadastro territorial: instrumento fundamental à gestáo social do município}

Os primeiros cadastros elaborados pela Administração Pública foram estruturados para equacionar o sistema de tributação. As bases de composição do denominado Cadastro Econômico registravam o valor da parcela e essa era utilizada para o cálculo do imposto territorial.

A maioria dos cadastros implementados atualmente, nos diferentes níveis de governo, ainda seguem esse mesmo objetivo. Entretanto, a necessidade de novos métodos de avaliação, baseada em detalhes mais construtivos, exige que as bases de dados sejam ampliadas para refletir a realidade da ocupação do solo urbano. Tais ampliaçóes se referem à identificação da localização, forma, dimensões e, principalmente, à funcionalidade dos imóveis urbanos. Esse mapeamento multifinalitário serve de instrumento apto a incrementar a valorização social da terra e o planejamento municipal de habitação, uma vez que fornece dados precisos para viabilizar a implantação de instrumentos urbanísticos (Erba, 2005).

$\mathrm{O}$ cadastro possui duas dimensóes funcionais: positiva, quando protege o direto de propriedade mediante a publicidade imobiliária, e negativa, quando restringe o poder de livre disposição do bem pelo titular em benefício do interesse público.

Portanto, é um instrumento capaz de contribuir com o cumprimento da função social da propriedade, assumindo o papel de polícia territorial com o poder de fiscalizar a funcionalidade dos imóveis que compóem o tecido urbano.

A tendência de elaborar cadastros com o fim de conhecer a cidade e as possibilidades de aprimorar o planejamento do espaço urbano não é tão recente. Recebeu muito incentivo a partir de junho de 1996, com a II Conferência das Naçôes Unidas sobre Assentamentos Humanos (HABITAT II), que reafirmou a necessidade de administrar corretamente o território para promover a segurança da moradia e acelerar os processos de desenvolvimento (Erba, 2005).

Com isso, fortalece-se a necessidade de inserir o cadastro no planejamento e desenvolvimento contemporâneo das cidades, principalmente para a promoção da moradia social. A função do cadastro tornou-se táo fundamental para o correto planejamento do espaço que a sua ampliação foi determinada no sentido de incluir as informaçóes ambientais e sociais às bases de dados econômicos, físicos e jurídicos. 
Esse processo, que começou a ser esboçado no final da Segunda Guerra Mundial consolidou-se posteriormente na nova visão de Cadastro Territorial Multifinalitário (CTM).

O sistema de elaboração de cadastro iniciou-se com uma visão puramente fiscal. Não delimita o direito de propriedade de cada parcela (menor unidade de registro) com precisão nem consegue identificar se o imóvel está efetivamente funcional. Também não mostra as limitaçôes impostas pelas normas de planejamento, tais como: servidóes administrativas, desapropriaçóes, parcelamentos e edificações compulsórias. Diante das falhas constatadas, tornou-se necessária a criação de um novo sistema de cadastro que trouxesse as informaçóes de forma mais ampla e integrada.

Em 2007, foi criado um grupo de estudos (GT-Cadastro) (Brasil, 2007) ${ }^{\mathrm{I}}$ para estudar a matéria e formular uma proposta de diretrizes compatível com a realidade diversificada dos municípios brasileiros, o que resultou em portaria $^{2}$ ministerial de caráter orientador (Brasil, 2009), que estabeleceu as diretrizes para a criação e atualização do CTM pelos municípios.

Esse sistema torna mais amplo o registro de dados no cadastro e o transforma em um inventário público metodicamente ordenado de todos os objetos territoriais legais de determinado país ou distrito, tomando como base a mensuração dos seus limites. Tais objetos legais identificam-se sistematicamente por meio de alguma designação, e a delimitação da propriedade e o identificador, junto à informação descritiva, podem mostrar, para cada objeto territorial, sua natureza, o tamanho, o valor e os direitos e, ou, restriçóes legais associadas a ele (Erba, 2005).

O novo sistema cadastral compreende desde as mediçóes, que representam toda a parte cartográfica, até a avaliação socioeconômica da população. Pretende mostrar a situação legal do território de forma completa, incluindo o direito público e as restriçóes, substituindo a cartografia tradicional pela modelagem cartográfica e digitalizando todo o sistema de informação.

Os aspectos considerados pelo CTM são: econômicos (variáveis que levam a determinar o valor do imóvel e do imposto), geométricos (como a localização, forma e dimensôes da parcela), jurídicos (que determinam a relação ho-

\footnotetext{
I. Portaria n. ${ }^{\circ}$ 516, de I6 de outubro de 2007, publicada no DOU de I7 de outubro de 2007.

2. Portaria Ministerial n. ${ }^{\circ}$ 5II, de 07 de dezembro de 2009, que institui Diretrizes para a criaçáo, instituição e atualizaçáo do CTM nos municípios brasileiros, DOU de 08 de dezembro de 2009.
} 
mem-parcela), sociais (que permitem delinear o perfil do proprietário ou possuidor) e ambientais.

Além desses fatores práticos, pretende viabilizar uma grande participação do setor privado, podendo até mesmo ocorrer a privatização total do cadastro com a consequente venda de dados a usuários e a possibilidade de reinvestimento e atualização na melhoria do sistema.

Essa forma técnica de conhecer o ambiente da cidade trará informaçóes precisas e fundamentais para a gestão territorial como um todo. Mais precisamente, no que se refere ao planejamento de habitação social, o cadastro conterá elementos indispensáveis que permitirão definir a melhor forma de aproveitar o tecido urbano já estruturado, contribuindo com a indicação dos imóveis ociosos. Sendo assim, o cadastro relaciona a realidade local com a possibilidade prática de implementação dos institutos do Estatuto da Cidade, funcionando como um liame entre o direito posto e a efetividade da lei.

À medida que os instrumentos urbanísticos forem sendo aplicados de acordo com os elementos indicados, eles farão parte do cadastro com as novas atualizaçóes. Estas, por sua vez, continuarão gerando o acompanhamento e a fiscalização dos gravames e, por consequência, a funcionalidade dos imóveis.

Esse percurso cadastro/política pública seria o resultado ideal da articulação entre os instrumentos. Assim, parece que todo esse arcabouço legal e prático soa como uma utopia urbana sustentada pelas perspectivas propostas. Entretanto, sinaliza-se que não é legítimo abdicar de projetos transformadores nem nos contentarmos em "fazer aquilo que é possível". Este jargão pode significar a reprodução do status quo alimentado pelas mesmas e perversas dinâmicas e relaçóes que dominam nossas cidades. A defesa de mudanças profundas está na ordem do dia. Transferir parte da produção e planejamento de habitação social para o poder público municipal implica enfrentamento do crescente déficit habitacional, retirando, de forma coerente, o protagonismo do setor da construção ao redirecioná-lo à valorização fundiária no rumo da função social.

Essa necessidade de transferência designa uma política de freios e contrapesos no sentido de o Estado oferecer um movimento de resistência alternativo e contrário à padronização da produção de moradia. Afinal, o domínio de um determinado sistema empobrece o alcance social e a diversidade de resultados que as açốes e programas governamentais são capazes de atingir.

Trata-se de requalificar o poder público como o termômetro social, equilibrando a atividade econômica e a justiça social, não permitindo que uma seja 
diminuída pelo outra - tal como a luta para retirar a cidade do controle dos especialistas e eliminar o monopólio tecnocrático sobre a cidade. Em outras palavras, a luta para democratizar a cidade e inserir um olhar mais sensível e humano, edificando os valores comunitários, históricos, culturais e as demais conquistas sociais.

Mais uma vez lembrando o pensamento de Lefebvre (2013), na sua obra Direito à cidade, na qual afirma que os problemas urbanos não podem ser resolvidos apenas na prancheta do arquiteto: há que existir um entrelaçamento de direitos e interesses diversos vindos dos vários segmentos sociais, para que todos sejam lembrados, e, assim, garantir que a noção de sistema não "engula" a noção de estratégia, a que melhor representa essa diversidade.

\section{A utilizaçáo do Cadastro Territorial Multifinalitário como instrumento de democracia e controle social}

Seguindo o encadeamento lógico de traçar estratégias a fim de garantir uma cidade para todos, passaremos a examinar a questão do conhecimento detalhado do tecido urbano como requisito essencial ao planejamento urbano e habitacional.

Dessa forma, já identificamos o CTM como um instrumento fundamental à Administração Pública, no exercício da sua governabilidade. Representa um recurso necessário à implementação de políticas públicas em razão da reserva de dados diversificada e integrada.

O levantamento cadastral aperfeiçoa a realização do planejamento municipal e proporciona mais transparência administrativa e fiscal para a população. Como exemplo, destaca-se o caso de Belém, amplamente discutido por Georgina Galvão e Mauro Gaia (2005), e cujas informaçóes e dados serão descritos nas linhas a seguir.

Os autores apontam o baixo desempenho da administração de Belém, que não se servia de nenhum mecanismo de integração entre os cadastros, utilizava informaçóes e modelos desatualizados e atuava com dados insuficientes para a elaboração de estratégias capazes de orientar a ação fiscalizadora e o correto lançamento dos tributos.

Relatam ainda que, em anos anteriores, houve uma tentativa desastrosa de recadastramento, cujas maiores consequências foram o lançamento de inscriçôes em duplicidade e uma significativa concentração de erros no setor fiscal de maior densidade populacional da cidade. 
O passo mais importante para a mudança estrutural da gestão municipal foi a implantação do CTM, que envolveu vários órgãos da administração, tanto para a definição do programa de necessidades quanto para a execução e acompanhamento do mesmo.

A partir de então, foi observado o aumento da arrecadação e de isenções fiscais, e o CTM se inseriu como instrumento de referência para viabilizar a implementação de políticas públicas nas mais diversas áreas de atuação, tais como: intervenções no sistema viário, drenagem, pavimentação, iluminação pública, sinalização viária, projetos de revitalização de áreas degradadas e de moradia.

A sua aplicação trouxe, como principal elemento de inovação, o rompimento com a lógica tradicional adotada na elaboração de cadastros municipais que possuem um viés desarticulado e limitado de informaçóes. Em contraste, o CTM produziu a universalidade de seu alcance e a elevação da base de dados, que foi alterada de 220 mil para 360 mil inscriçóes imobiliárias, perfazendo um aumento em torno de $6 \mathrm{I} \%$ em relação ao cadastro anterior.

$\mathrm{O}$ cadastramento dos imóveis foi realizado com foco nas múltiplas potencialidades apontadas à gestão municipal e não apenas no interesse fiscal. Dessa forma, foram cadastradas tanto as áreas valorizadas quanto os assentamentos populares sem infraestrutura, tradicionalmente desconsiderados pelas empresas de aerofotogrametria e levantamento cadastral, que costumam representá-los no mapa por meio de manchas com a denominação de favela.

A partir da decisão política de cadastrar todos os imóveis localizados na área urbana do município, afastando o interesse meramente arrecadatório, foi necessário realizar um estudo de redistribuição fiscal, a fim de equilibrar a carga tributária no sentido de desonerar os ônus tributários incidentes sobre os imóveis urbanos que cumprem sua função social, bem como de reconhecer a isenção daquelas propriedades residenciais de baixo valor patrimonial para o mercado imobiliário.

Com os primeiros resultados obtidos pela implantação do CTM, foi possível, através da Lei n. ${ }^{\circ} 7.986$ de 30 de dezembro de 1999, ampliar para 9 mil UFIR (equivalente a $\mathrm{R} \$ 9.576,90$ ) o limite da isenção automática. Essa medida permitiu, já no lançamento do IPTU 2000, elevar para 84.264 o número de contribuintes isentos que até 1999 somavam apenas I6.I73 (em torno de 7\% do total cadastrado). Isso foi conseguido sem que houvesse redução na arrecadação, ou seja, o aumento do número de imóveis cadastrados, bem como a atua- 
lização das benfeitorias dos imóveis anteriormente registrados, compensou a ampliação do universo de imóveis beneficiados pela isenção automática (Galvão e Gaia, 2005, p. I23).

A redistribuição da carga tributária alcançada com a conclusão do CTM permitiu o aumento nominal do limite de isenção, elevando para 49\% o número de contribuintes isentos no novo cadastro, e uma elevação na arrecadação do IPTU junto com taxas agregadas em $\mathrm{R}$ \$22,6 milhôes, em I996, para R\$39,0 milhóes, em 2003, mesmo com 179 mil imóveis isentos, em um total de 360 mil. Para se cobrar o IPTU levando em consideração a capacidade contributiva dos cidadãos, tornou-se absolutamente imprescindível ter uma base cadastral confiável dos imóveis (Galvão e Gaia, 2005).

O novo cadastro possibilitou, ainda, que as áreas da cidade, que historicamente sempre receberam maior aporte de investimentos, passassem a participar com uma contrapartida maior e mais condizente com os benefícios recebidos: afinal, podem suportar alíquotas superiores. Em contrapartida, possibilitou que áreas anteriormente muito valorizadas, e que passavam por processos de degradação, quase sempre resultantes de modelos de urbanização inadequados, tivessem seus valores ajustados à nova realidade.

É importante destacar que o crescimento das receitas municipais não se deu por aumento no valor dos tributos, mas pela aplicação de uma política de justiça fiscal, exigindo-se tributos de quem pode pagar, isentando quem náo tem capacidade contributiva, corrigindo bases de cálculos, sem, contudo aumentar o valor das alíquotas (Galvão e Gaia, 2005, p. I28).

A partir do mapeamento multifinalitário, o município poderá protagonizar o desenvolvimento e crescimento da cidade, sem se tornar refém do mercado de construção, que se antecipa em determinar para onde a cidade deve crescer, produzindo o espaço urbano de acordo com seus empreendimentos e interesses de lucro.

Essa dinâmica do setor privado traça previamente o seu planejamento de execução, realizando vários estratagemas de ação, tais como: investir especulativamente no mercado imobiliário, adquirindo um "banco de terras" para o futuro; formando aliados políticos, por meio do financiamento privado de campanhas; e participando da elaboração de programas governamentais.

Esse encadeamento de atos perpetrados pela iniciativa privada assume o papel de plano de investimento do empresariado. Da mesma forma, cabe ao poder municipal a tarefa de planejar suas açóes futuras conhecendo o próprio 
terreno de ação por meio do mapeamento urbano, tornando possível detectar a melhor forma de aproveitamento do tecido urbano para a implementação de instrumentos urbanísticos de gestão social e crescimento da arrecadação.

A aplicação desses instrumentos somados a uma efetiva tributação pode contribuir para o aumento do recurso público vinculado ao financiamento de habitação e melhoria de serviços e infraestrutura, gerando, com isso, uma maior autonomia do município. Atualmente, o mercado de construção detém o protagonismo da produção de moradia em razão da própria construção da Lei n. ${ }^{\circ}$ II.977/o9 que dispóe sobre o programa Minha Casa, Minha Vida, uma vez que permite a hegemonia do mercado na corrida das contrataçóes.

Logo, o empreendedorismo privado prevalece-se da permissão legal e operacionaliza uma oportunidade de alto lucro e pouco risco. Entretanto, cabe salientar que essa hegemonia privada acontece porque náo depara-se com uma resistência contrária suficientemente forte para direcionar e controlar essa produção de espaço urbano. O domínio de mercado leva a uma precarização de resultados (baixa qualidade, periferização, capitalização da moradia, ausência de infraestrutura, exclusão de cidadania) e maximização de lucros em decorrência da ausência de alternativas concretas.

Diante desse quadro, cabe ao poder público entrar nessa produção diretamente ou por meio de mecanismos jurídicos e urbanísticos de planejamento, com o fim de interferir incisivamente no direcionamento do crescimento da cidade e seu desenvolvimento social. Se a resposta ao déficit habitacional restar exclusivamente nas mãos do mercado, que visa somente ao lucro, cai por terra a ideologia constitucional da função social e todas as suas conquistas.

Ressalta-se, ainda, que o direcionamento da política urbana pode influenciar na diminuição da alta dependência de recursos advindos das transferências de outros níveis governamentais. É uma situação que fragiliza a autonomia dos municípios e estimula os administradores a desempenharem um papel passivo diante das dificuldades financeiras, aguardando por uma política nacional para a resolução dos problemas enfrentados em nível local.

Ao observar o "passo a passo" para a reestruturação da habitação social, percebe-se que esta deve ser iniciada pelos imóveis ociosos que compóem o tecido urbano já infraestruturado. Para tanto, o governo deve encarar seu papel de titular da política urbana e trabalhar em conjunto com os diversos atores sociais, buscando o equilíbrio de interesses e a harmonia de resultados, de forma a não submeter o direito à moradia ao lucro de mercado. 


\section{Imóveis ociosos: o município de Petrópolis como caso de referência}

Este capítulo explora os resultados de uma pesquisa de campo realizada na cidade de Petrópolis, Regiáo Serrana do Rio de Janeiro, com o objetivo de utilizá-la como caso de referência nesse estudo. A pesquisa visa estabelecer um parâmetro exemplificativo que possibilite demonstrar, de forma prática, a incoerência provocada pelo desconhecimento do tecido urbano da política habitacional.

Apesar da enorme importância de todos os tipos de ociosidade imobiliária apresentada no tecido urbano das cidades, a pesquisa limita-se à identificação de terrenos vagos (não construídos) nos referidos bairros centrais. Essa escolha se explica em função da grande dificuldade em identificar o não uso ou a subutilização sem o auxílio do poder público.

\section{I. O município de Petrópolis (RJ)}

A cidade de Petrópolis se desenvolveu a partir da exploração da atividade industrial, chegando a implementar o mais importante polo têxtil do país, onde foram instaladas as fábricas: Imperial Fábrica de São Pedro de Alcântara, Companhia Petropolitana, Aurora, Werner, Santa Helena, Dona Isabel e a Cometa.

No final do século XIX, possuía cerca de 29 mil habitantes, atingindo o ápice de 35 mil no verão. Desde a sua fundação até os dias de hoje, manteve as características de abrigar casas de segunda residência das camadas de média e alta renda da sociedade carioca, constituindo-se também em um intenso polo turístico, que gerou uma forte ligação com o Rio de Janeiro (Petrópolis, 20I2).

$\mathrm{Na}$ década de 1960, inicia-se o processo de perda das indústrias e a migração de investimentos do setor têxtil para a cidade de São Paulo e para a Região Nordeste, em especial Paraíba e Bahia. Com isso, esvaziou-se a principal atividade econômica do município, com a indústria sendo substituída pelas atividades de comércio e serviços, atuais motores da economia petropolitana. Ainda que tenha perdido dinamismo, a população atingiu 295.917 habitantes, de acordo com o Censo Demográfico de 20ı, parte da qual enfrenta dificuldades para ter acesso ao direito constitucional à moradia. 
Tabela I - Distribuição da população nos distritos do município de Petrópolis, 20 IO

\begin{tabular}{ll} 
DISTRITO (\%) & POPULAÇÃO \\
\hline Petrópolis (63\%) & I85.876 \\
\hline Cascatinha (23\%) & 64.936 \\
\hline Itaipava ( 7\%) & 20.444 \\
\hline Pedro do Rio (5\%) & I4.079 \\
\hline Posse (3\%) & 10.582 \\
\hline TOTAL & 295.917 \\
\hline
\end{tabular}

Fonte: Prefeitura Municipal de Petrópolis, 20II, com base no Censo IBGE, 2010.

O município integrou a Regiāo Metropolitana do Rio de Janeiro de I974, época de sua criação, até 1993, momento em que foi integrado à Região Serrana pela nova divisão de Regióes de Governo do Estado. Sua extensão territorial abrange $795,8 \mathrm{~km}^{2}$, contando com uma população total de 295.917 habitantes, sendo 95\% urbana, e densidade demográfica de 371,85hab $/ \mathrm{km}^{2}$ (IBGE, 20Io). É composto por cinco distritos: Petrópolis $\left(\mathrm{I}^{\mathrm{o}}\right)$, Cascatinha $\left(2^{\circ}\right)$, Itaipava $\left(3^{\circ}\right)$, Pedro do Rio $\left(4^{\circ}\right)$ e Posse $\left(5^{\circ}\right)$. A maior parte da população $\left(63^{\circ}\right)$ está concentrada no distrito de Petrópolis, que detém o maior volume de atividades econômicas, empregos, equipamentos públicos, infraestrutura e serviços, representando a área mais consolidada e de ocupação mais antiga.

\subsection{Desafios da política habitacional em Petrópolis}

Em 20I2, o município apresentou um déficit quantitativo habitacional acumulado de II.828 moradias, sendo 5.213 em assentamentos precários e 6.616 fora destes. ${ }^{3}$ Segundo o seu Plano Local de Habitação de Interesse Social (PLHIS), elaborado no mesmo ano, estimou-se uma inadequação habitacional (qualitativa) de 2I.395 domicílios com algum tipo de carência ligada à infraestrutura ou regularização fundiária, e ainda II.568 residências classificadas como unidades de risco alto ou muito alto, em relação ao escorregamento de encostas (Petrópolis, 20I2).

3. Plano Local de Habitação Social de Petrópolis. 20I2, pp. I38, I44 e I45. 
Tabela 2 - Resumo do déficit habitacional dentro e fora de assentamentos precários

DOMICÍLIOS

Déficit habitacional quantitativo em assentamentos precários

Déficit habitacional quantitativo fora de assentamentos precários

Inadequação habitacional qualitativa em assentamentos precários

TOTAL
TOTAL

5.213

6.615

$2 \mathrm{I} .395$

33.223

Fonte: PLHIS do município de Petrópolis, com base na elaboração de DEMACAMP Planejamento, Projeto e Consultoria Ltda. 2012.

A situação de risco surge em razão de a cidade ter sido construída entre montanhas que apresentam um alto índice de risco geológico por condicionantes naturais, e ainda pela densa ocupação de suas encostas após a década de 1950. Essa soma de fatores transforma parte do território urbano em uma grande área de situação de risco, principalmente aquela compreendida pelo Primeiro Distrito, local que concentra a maior parte da população (63\%), cujo relevo é mais acidentado. Quanto às peculiaridades descritas, essa área abriga no seu tecido urbano seis favelas, classificadas como não consolidáveis, em razão do risco de desabamento das encostas, contabilizando 2.786 habitaçóes em risco muito alto e 4.290 em risco alto, apresentando os piores níveis de risco do município (Petrópolis, 20I2, pp. 129-30).

O PLHIS define uma demanda de terra de $362.625 \mathrm{~m}^{2}$ para combater o déficit de 2.994 moradias (Petrópolis, 20I2, p. I53) dentro dos assentamentos precários do Primeiro Distrito. Acontece que as moradias em situação de risco situadas naquela área, segundo os dados acima apresentados, somam 7.076 residências, restando, portanto, um saldo de 4.082 moradias em risco sem respaldo no planejamento municipal.

A partir dos dados apresentados acima, percebe-se que a maioria dos imóveis em situação de risco não consta no planejamento de habitação do município. Da mesma forma, não consta no PLHIS o manejo de imóveis ociosos, ou ao menos a identificação destes, para compor a política habitacional. Com isso, retira a possibilidade de incluir um importante potencial fundiário da cidade para contemplar a promoção de moradia social. Cabe salientar a existência de imóveis ociosos em áreas centrais do Primeiro Distrito, contando com infraestrutura e serviços públicos sedimentados, como adiante será demonstrado.

Parece claro que um dos elementos fundamentais para a produção de Habitação de Interesse Social é a disponibilidade de terra urbana apta a re- 
ceber os empreendimentos. O PLHIS de Petrópolis define "terras aptas" como os terrenos bem localizados na cidade que possuam boa acessibilidade e suficientes equipamentos públicos para servir à população moradora. Além disso, devem apresentar uma infraestrutura urbana compatível com o adensamento que será provocado pelos novos empreendimentos habitacionais.

Observa-se que o déficit de moradia é uma questão urbana complexa que deve ser enfrentado com a utilização de todos os recursos locais possíveis, mas, apesar disso, o PLHIS não inclui a identificação dos imóveis ociosos como mais um mecanismo apto a compor a política habitacional. Para aproveitar o potencial fundiário do seu tecido urbano, o caminho a ser percorrido pelo poder público é a implementação de um cadastro territorial que permita a identificaçáo dos vários tipos de imóveis ociosos que compõem o território do município. Essa identificação facilitaria a articulação de formas personalizadas de produção do espaço urbano mais adaptadas às condiçóes e características locais, contribuindo para romper com o padrão único de moradia oferecido pelo mercado e a autoconstrução desordenada das áreas urbanas.

Não é essa a experiência da política habitacional no Brasil. Nas palavras de Raquel Rolnik para o Jornal Folha de S. Paulo em publicação de 5 de outubro de 20I5:

$\mathrm{Na}$ arquitetura das edificações predominam os "puxadinhos" ou os "edifícios-carimbo", reproduzidos ad infinitum, independentemente do lugar e do clima onde estão inseridos. São, de um lado, casas e comércios construídos pelos próprios moradores, de outro, no setor privado e nos programas governamentais de habitaçáo, são projetos elaborados não sob a lógica da qualidade arquitetônica, mas da garantia da rentabilidade do negócio frente aos valores subsidiados pelos programas e os limites de renda dos compradores.

Petrópolis revela a realidade presente em grande parte dos municípios brasileiros, isto é, uma gestão municipal que desconhece o próprio tecido urbano ao planejar sua política habitacional e, com isso, parte de diagnósticos incompletos para executar um planejamento habitacional que frequentemente está desvinculado das condiçóes locais da cidade. Essa dinâmica contraria o sentido da Portaria n. ${ }^{\circ}$ 5II/o9 do Ministério das Cidades que determinou diretrizes 
para a criação, instituição e atualização do CTM nos municípios brasileiros ${ }^{4}$ como instrumento útil à gestão pública municipal.

Como já referido, a cidade de Petrópolis possui um relevo acidentado com diferentes situaçóes topográficas e movimentos de terra que tornam a maior parte de seu território inadequado à construção de grandes conjuntos habitacionais. Estes demandam uma paisagem uniforme, de pouca diversidade, bem diferentes da realidade territorial petropolitana, que impóe a técnica de projetos desenvolvidos especificamente para o aproveitamento do seu relevo. Com isso, observa-se uma relação de virtual impossibilidade entre a reprodução da lógica de construção de grandes condomínios e a escassez de terra adequada a este padrão que o município oferece.

Frequentemente, o município sofre com desabamentos provocados pelas chuvas de verão, o que resulta em graves perdas sociais e muitos desabrigados. ${ }^{5}$ No ano de 20II, uma catástrofe assolou parte do seu território e de outros 19 municípios da Regiấo Serrana, o que resultou em 9I8 mortes, mas esti-

\footnotetext{
4. Art. 32 - A adoçáo de um Cadastro Territorial Multifinalitário completo e atualizado auxiliará os Municípios brasileiros a exercerem suas competências prescritas nos arts. 30 e 156 da Constituição Federal de 1988, cumprindo a função social do seu território, prevista no texto constitucional, artigos $5^{\circ}$, inciso XXIII, $3^{\circ}$, incisos I a IV, 30 , inciso VIII, I70, inciso III, I82 e 183, atendendo ao princípio da igualdade, nos termos dos arts. $5^{\circ}$, caput e I50, inciso II da Constituiçăo Federal de 1988.

Art. 34 - O Sistema de Informaçóes Territoriais destina-se a fornecer as informaçôes necessárias para a utilização dos instrumentos da política urbana previstos no art. $4^{\circ}$ da Lei I0.257, de Io de julho de $200 \mathrm{I}$ - Estatuto da Cidade.

Art. 37 - A existência de um Cadastro Territorial Multifinalitário atende às Diretrizes Gerais de Política Nacional de Desenvolvimento Urbano, Diretriz n. ${ }^{\circ}$ I2s e Resoluçôes da $2^{\mathrm{a}}$ e da $3^{\mathrm{a}}$ Conferência Nacional das Cidades, instrumentalizando a construçấo de um "Sistema Nacional de Política Urbana", por meio das quatro vertentes: planejamento territorial; habitação; saneamento ambiental; trânsito, transporte e mobilidade urbana, com controle e participação social.

5. "Desde a noite de domingo, já são 498 as ocorrências registradas pela Defesa Civil. Há dois anos, 876 famílias vivem do aluguel social na cidade. O total de mortos desde a noite de domingo, em Petrópolis, chegou a 27 na tarde desta terça-feira. Ainda há cerca de ro desaparecidos que, de acordo com equipes da Defesa Civil, podem ser de pessoas que ficaram sob os escombros em uma das 2I áreas desmoronadas. Em meio a medidas emergenciais, busca de corpos e anúncios de liberaçấo de verba, a população de Petrópolis assiste, mais uma vez, ao triste espetáculo da cidade que se desmancha: mais encostas rolaram, mais casas estão sendo interditadas e até o momento não houve entrega - ou construçáo - de uma casa sequer, entre os II2 apartamentos prometidos pelos governos federal e estadual. Desde a chuva de janeiro de 20II, 876 famílias recebem aluguel social - mas dentro de pouco tempo não haverá sequer o que alugar, dado o ritmo do trabalho de reconstruçấo. Já são 498 as ocorrências registradas pela Defesa Civil. O local mais atingido pelas chuvas, o bairro Quitandinha, recebeu em 36 horas um volume de chuva equivalente a 499 milímetros, quase o dobro do esperado para todo o mês de março, que era de 270 milímetros. Os números e estimativas não cabem mais na realidade da Regiāo Serrana do Rio. Desde a madrugada de I2 de janeiro de 2oII, Nova Friburgo já teve ruas alagadas diversas vezes; Teresópolis teve novas mortes, em Io de maio de 20I2; e, agora, Petrópolis revive a tragédia”" (Ritto, I9 de março de 2013).
} 
ma-se que esse número seja bem superior. ${ }^{6}$ Por sua vez, o governo municipal, rendendo-se ao PMCMV como forma de política habitacional, justificou sua inércia em produzir moradia com a verba federal disponibilizada sob o argumento de que faltavam terrenos adequados para a construção de moradias no formato do programa. Afinal, os empresários negavam-se a empreender na cidade, diante do alto custo para preparar os terrenos (Haubrich, 20I5). Isso revela como o poder municipal comporta-se de forma dependente diante do governo federal e suas fórmulas prontas das políticas públicas.

Um cadastro territorial bem elaborado detém em seus registros uma grande base de dados e, com isso, instrumentaliza o planejamento da política urbana e facilita o controle do território municipal, além de contribuir com a elaboração e gestão de políticas públicas. Essa dinâmica fortalece o protagonismo do poder municipal na mediaçáo de projetos habitacionais com a iniciativa privada, uma vez que, por meio da gestão dos instrumentos disponíveis o município pode formar seu próprio "banco de terras", oferecendo aos incorporadores terrenos mais centrais para moradia social.

Da mesma forma, o fundo municipal para habitação de interesse social poderia ser alimentado pela gestão social do seu território por meio da aquisição de terrenos e a produção de moradia. Além disso, o fortalecimento da autonomia municipal nessa política possibilitaria o rompimento da lógica de concentração da produção habitacional em poucas empresas, prática mercantil que impõe a padronização de preços no mercado imobiliário visando ao aumento da rentabilidade do negócio. Nessas condiçôes, a diminuição da mercantilização da política habitacional de interesse social contribuiria para maior diversificação da produção, assim como do barateamento de seus custos (Cardoso e Aragão, 2013).

Essa concentração de mercado pode ser exemplificada no caso do Rio de Janeiro, onde apenas dez empresas foram identificadas como responsáveis por

\footnotetext{
6. "Lista oficial diz que 918 morreram em Petrópolis, Teresópolis e Friburgo. Enchentes de 201 I fizeram cerca de IO mil vítimas, segundo associaçôes. A suposta subnotificação de mortes foi identificada através de relatos de pessoas que moravam nas áreas atingidas e que não conseguiram oficializar a perda de parentes.

Divergência de números.

Além do relato de parentes, as entidades levam em conta a divergência entre o número computado de mortos em determinadas localidades e a quantidade de "relógios de luz" que havia nestes locais, segundo a própria concessionária de energia elétrica, a Ampla. 'Acreditamos que aproximadamente io mil pessoas foram afetadas. Haver pouco mais de mil [mortos e desaparecidos], como é divulgado, é um número irreal pela proporção da tragédia." (Canejo, io de agosto de 20I5).
} 
65\% da produção habitacional (Cardoso e Aragão, 2013), e ainda, no caso de Fortaleza, em que apenas duas construtoras detêm 70\% desse mercado. Segundo Rufino (20I3), as grandes empresas de construção nacionais e locais tendem a associar-se, criando sociedades de propósitos específicos para gerenciar os empreendimentos. Isso fortalece ainda mais a concentração do mercado e, assim, as soluçôes em grande escala a que já fizemos referência.

A adaptação de projetos habitacionais à realidade local com custos reduzidos é viável, como sugere o estudo de Frajndlich (20I2). Este ocorreu no município de Caruaru (PE), onde o escritório Jirau Arquitetura elaborou um projeto específico para a construção de um bairro popular ${ }^{7}$ utilizando conceitos construtivos da tradicional técnica local, além de uma boa leitura do terreno, de suas condicionantes de implantação e da criação de uma nova fachada. Esse conjunto de decisóes resultou em um empreendimento personalizado que rompe com a lógica repetitiva da habitaçáo social. O exemplo citado sugere a possibilidade de que o poder público exerça o controle efetivo do planejamento urbano, promovendo uma política habitacional coerente e estimulando projetos que se adaptem às condiçóes e realidades locais. Um compromisso municipal dessa natureza com a gestão social de seu território daria maior efetividade à política local de habitação de interesse social.

\subsection{Pesquisa de campo: mapeando imóveis ociosos em áreas centrais de Petrópolis}

Petrópolis elaborou seu diagnóstico sobre a situação de moradia no primeiro distrito do município, mas não fez referência à atualização de cadastro territorial nem à inclusão de imóveis ociosos na estrutura da sua política habitacional. Observa-se que um cadastro bem elaborado identifica as várias categorias de ociosidade imobiliária do tecido urbano, isto é, indica, de acordo com a le-

7. Bairro habitacional desenhado pela Jirau Arquitetura em Caruaru, Pernambuco, cria nova referência de casas econômicas na cidade. O projeto optou por paredes altas e coberturas inclinadas, formando uma sucessão de cores. As casas foram implementadas de modo escalonado no terreno acidentado permitindo ao observador que sinta o movimento das paredes e o volume colorido das caixas d'água ao caminhar pela vila. As residências foram construídas em forma de "S" com dois dormitórios, sala e cozinha. O formato desalinhado traduz-se como uma estratégia para controlar a funcionalidade da planta e a linha estética original do projeto diante das possíveis alteraçôes que os moradores geralmente fazem. A proposta do projeto comporta a abertura de um quarto extra que se abriria para o quintal, assim as alteraçôes não descaracterizam a fachada nem interferem na alvenaria e cobertura do conjunto. 
gislação local, os imóveis classificados como terrenos vagos, edificados, mas desocupados e subutilizados.

Nesse contexto, percebe-se que o poder público municipal ao elaborar o PLHIS mostra desconhecimento no potencial fundiário da própria cidade. Isso pode ser observado pela falta de mapeamento da área urbana, e também pela listagem de terrenos apresentados para compor a política habitacional do município, 22 ao todo, ${ }^{8}$ distribuídos por todos os seus distritos. Nota-se que essa lista não inclui os imóveis ociosos identificados pela pesquisa de campo, o que leva à possibilidade de existir mais terra urbana compatível com a gestão social da valorização fundiária.

As palavras inscritas no PLHIS do município de Petrópolis (2012, p. 154) confirmam o desconhecimento do seu potencial fundiário ao afirmar que:

a população, por sua vez, também afirmou conhecer terrenos vazios que poderão ser utilizados para a provisão de novas unidades habitacionais de interesse social. A Prefeitura deverá aprofundar as informaçóes sobre os terrenos vazios aptos no intuito de reservá-los para futuros empreendimentos de HIS.

Diante disso, observa-se que o poder municipal atua em função de um plano incompleto, por desconhecer o próprio tecido urbano. Cabe ainda destacar que os terrenos selecionados pela listagem seguem o perfil adotado pela lógica do mercado de construção, isto é, grandes terras afastadas dos centros para sediar conjuntos habitacionais. Tal abordagem é reveladora de um comportamento que impede uma gestão social integrada às potencialidades locais ao preferir selecionar de forma aleatória terrenos que atendam ao planejamento do mercado.

Ao tratar dessa forma a política habitacional, o município não correlaciona a realidade do déficit habitacional com a sua competência sobre a gestão de

8. Estrada Uniáo e Indústria, I2.089, Pedro do Rio $\left(15.000 \mathrm{~m}^{2}\right)$; Fazenda San Joaquim, gleba 05, Vale do Cuiabá (Io.ooom²); Estrada João de Oliveira Botelho, Itaipava-Santa Mônica (ıo.ooom²); Estrada Caetitu, s/n, bairro Caetitu $\left(15.000 \mathrm{~m}^{2}\right)$; Estrada Luiz Gomes da Silva, 893 , Caetitu $\left(\mathrm{I} 5.000 \mathrm{~m}^{2}\right)$; Estrada Philuvio Cerqueira, Itaipava $\left(\right.$ (o.oom $\left.{ }^{2}\right)$; Rua Henrique Paixão, morro do Calango, bairro Itamarati $\left(2000 \mathrm{~m}^{2}\right)$; BR 040, Pedro do Rio (50.00om²); Estrada Philuvio Cerqueira, 20I6, Itaipava $\left(20.000 \mathrm{~m}^{2}\right)$, Estrada Ministro Salgado Filho, Vale do Cuiabá $\left(20.000 \mathrm{~m}^{2}\right)$; Estrada Caetitu, Eduardo Silverio, $\left(8.00 \mathrm{om}^{2}\right)$; Rua João Xavier, Ior5, bairro Duarte da Silveira (Io.ooom²); Rua Ângelo João Brandt, Quarteirão Italiano (48.0oom²); Estrada do Caetitu/Vale dos Esquilos, bairro Retiro (40.00om²); Pista de Esqui, bairro Floresta (I5.00om²); Estrada Independência, clínica Pedras Brancas (25.00om²); Rua Vassouras, quadra 83, bairro Quitandinha (6.0oom²); Rua Quissamă, s/n, depósito da Seobras, bairro Quissamã $\left(6.00 \mathrm{~m}^{2}\right)$; Rua Quissamã, floricultura, bairro Quissamã $\left(8.000 \mathrm{~m}^{2}\right)$; Estrada Almeida Amado, bairro Caxambú $\left(20.00 \mathrm{om}^{2}\right)$; Alberto de Oliveira, bairro Mosela (8.0oom²) (PLHIS do Município de Petrópolis, 20I2, p. I54). 
seu território para fins de moradia. Isso seria possível com a elaboração de um cadastro territorial atualizado de toda área urbana, o que permitiria selecionar terrenos para habitação de acordo com o déficit de cada região, a fim de alocar os moradores próximo à sua morada de origem. Essa correspondência de fatores facilitaria o alcance da inclusão socioespacial da cidade e o reconhecimento da população empobrecida.

$\mathrm{Na}$ busca de escolher terrenos que atendam ao perfil do mercado, o poder municipal desconsidera outros tantos que podem compor uma política habitacional diversa do padrão do mercado imobiliário, como será adiante demonstrado pela pesquisa de campo realizada em três bairros de Petrópolis.

Ao render-se à produção habitacional planejada pelo mercado, a administração municipal confirma o processo de "periferização" da moradia e o crescimento extensivo da cidade. Esse ciclo vicioso exemplifica-se pelos dois terrenos desapropriados pela Prefeitura para a construção de conjuntos habitacionais do PMCMV para a faixa de renda até $\mathrm{R} \$ \mathrm{I}$.600,00.

O primeiro terreno encontra-se localizado na Estrada do Caititu, uma área distante do $2^{\circ}$ distrito, sem infraestrutura e equipamentos públicos básicos, mas que atende ao padrão das construtoras por possuir uma superfície de $15.000 \mathrm{~m}^{2}$ e contar com o apoio do poder público para levar a infraestrutura necessária aos futuros moradores. ${ }^{9}$ Essa iniciativa reproduz com nitidez o antigo processo de "periferização" e crescimento horizontal das cidades do antigo Sistema $\mathrm{BNH}$, o que sugere a urgência em romper com essa lógica. ${ }^{\mathrm{IO}}$

\footnotetext{
9. "O prefeito Rubens Bomtempo vistoriou nesta semana as obras de pavimentação e drenagem da Estrada Luiz Gomes da Silva. As intervençóes vão permitir a ligaçáo entre os bairros Carangola e Corrêas, abrindo uma rota alternativa entre as duas importantes regiōes do município. Ambas receberão novos conjuntos habitacionais. $\mathrm{O}$ investimento é superior a R \$ I,696 milhão e faz parte do convênio com o governo do Estado, por meio do Programa Somando Forças. 'Queremos aproximar esses dois conjuntos e agregar valor aos bairros não só com as melhorias em infraestrutura, como também com a instalaçấo de novos equipamentos públicos. A ideia é que a escola, o centro de educação infantil, o posto de saúde e o centro de referência em assistência social que serão construídos pela Prefeitura atendam de forma integrada as duas comunidades'”, disse o prefeito (Petrópolis, 20I4).

IO. Sistema estruturado a partir da construçâo de conjuntos habitacionais nos pontos mais distantes da periferia, criando verdadeiros bairros dormitório, com o pretexto de que aqueles eram os únicos lugares que ofereciam, ao mesmo tempo, terra barata e adequada à produção em larga escala. Esta lógica leva ao forçado crescimento horizontal das cidades representado tanto pelos investimentos em infraestrutura básica para alcançar tais conglomerados, quanto pelo natural desenvolvimento das dinâmicas urbanas advindas da população transferida. Nas palavras de Bonduki (2000, p. 2I), "caracterizam-se, em geral, pela monotonia de sua arquitetura; pela ausência de relaçâa com o entorno; por sua localizaçáo periférica, estendendo horizontalmente as cidades; pela despreocupaçáo com a qualidade dos projetos e com o meio físico, resultando na depredaçấo ambiental [...]".
} 
Na mesma linha de atuação, encontra-se o segundo empreendimento, também do PMCMV. Este se localiza na Rua Vicenzo Rivetti, em área distante dos centros urbanos, mas relativamente próxima ao projeto citado acima, o que possibilita o aproveitamento da infraestrutura aos dois empreendimentos. Cabe ressaltar que a contrapartida da Prefeitura com relação a esse conjunto habitacional é a abertura de uma rua ligando o novo conjunto habitacional à localidade do Caititu, além da preparação do terreno com terraplanagem e fundação. ${ }^{\text {II }}$

Essas iniciativas evidenciam que a pouca iniciativa municipal para executar projetos habitacionais não está vinculada, necessariamente, à ausência de recursos financeiros: afinal, os custos em infraestrutura e preparação do terreno são altos. Portanto, parece possível à Prefeitura implementar políticas de habitação próprias, geradas a partir de uma gestão social da valorização fundiária. Essa autonomia em relação ao mercado imobiliário poderia romper com o paradigma do crescimento urbano extensivo e permitir o maior adensamento de áreas centrais.

A força que o mercado da construção exerce sobre o controle e a produção da habitação reflete-se na padronização urbanística, "periferização" da moradia, protagonismo na política habitacional e direcionamento do crescimento das cidades. O objetivo de todas essas açóes é produzir com rentabilidade unidades habitacionais. Nessas condiçôes, não causa estranheza verificar, com Lúcia Schimbo (2010), que os empreendedores preferem produzir moradias para as faixas superiores de renda, dado que geram maior rentabilidade, motivo pelo qual evitam aquela faixa onde se concentra o maior déficit habitacional, voltada para aqueles adquirentes com renda inferior aos $\mathrm{R} \$ \mathrm{I} .600,00$.

Essa realidade não é diferente no município de Petrópolis, já que, dos oito empreendimentos do PMCMV planejados para a cidade, seis contemplam a

II. “O prefeito Rubens Bomtempo vistoriou nesta sexta-feira as obras de construção das 778 unidades habitacionais do Programa Minha Casa, Minha Vida que serão erguidas no Vicenzo Rivetti, no bairro Carangola. No terreno, o serviço de terraplanagem já está sendo concluído e a expectativa é que a partir do mês de junho seja iniciada a fase de fundação. O investimento é de $\mathrm{R} \$ 63$ milhōes. A obra está sendo executada pela Construtora Andrade Almeida e durante a visita, acompanhado pelos secretários de Habitação, Rodrigo Seabra e o de Obras, Aldir Cony, Bomtempo discutiu a contrapartida do município. Um dos pontos foi o terreno a ser utilizado para a abertura de uma rua ligando o novo conjunto habitacional à localidade do Caititu, onde também existe a previsão de implantação do Programa Minha Casa, Minha Vida. 'São medidas importantes, pois garantirão toda a infraestrutura necessária para a população. Fazer um pouco mais pelo povo é o que justifica o nosso terceiro mandato. Somos um governo popular e que tem como prioridade atender a quem está por último na fila’, ressaltou. Além de Centro de Educação Infantil, uma nova escola com capacidade para atender quase mil alunos, um Posto de Saúde e um Centro de Referência em Assistência Social (Cras) também serão implantados no local" (Petrópolis, I7 de junho de 20I4). 
faixa de renda 02 do Programa. ${ }^{\mathrm{I2}}$ Os dois projetos de habitação social que conferem moradia para a faixa or localizam-se na Estrada do Caititu e na Rua Vicenzo Rivetti, como já mencionado.

Essa preferência pelas faixas de maior renda também afeta a política habitacional petropolitana, pois corre-se o risco de perder um dos empreendimentos destinados à faixa or do programa. De acordo com uma publicação da imprensa local, ${ }^{13}$ desde novembro de 2015 tramita, na Câmara dos Vereadores, um projeto de lei que determina a desafetação do terreno da Estrada do Caititu, para que este passe a sediar um conjunto habitacional destinado à faixa 02 de o PMCMV. O argumento utilizado pelo legislativo municipal está respaldado no fato de que a desapropriação tem mais de dois anos e as obras ainda não foram iniciadas (Barroso, 2015).

Essas dificuldades, ligadas à opção de produzir moradia por meio de um formato único, leva ao questionamento da manutenção dessa escolha. Afinal, apesar de o PMCMV guardar diferenças em relação ao Sistema BNH, suas semelhanças também se refletem diante do padrão de produção, localização na periferia urbana e o não alcance da população de baixa renda. Mudar tal orientação e definir uma gestão social da valorização fundiária possibilitaria construir uma política habitacional coerente às condiçóes locais de cada cidade, o que poderia levar a execução de projetos alternativos de habitação social de menor monta. Dessa forma, além de desvincular a produçáo de moradia do formato de grandes condomínios, também seria facilitada a administração e a conservação das habitações pelos moradores.

O município de Petrópolis possui um déficit habitacional quantitativo de II.828 moradias (Tabela I - Resumo do déficit habitacional), sendo que 5.2I3 destas localizam-se em assentamentos precários, entre as quais, 2.994 estão no

I2. "O PMCMV vai garantir mais 840 apartamentos em Petrópolis, através de três empreendimentos: um no Bingen, outro no Morin e em Pedro do Rio. O Programa é voltado para famílias com renda bruta entre R \$ I,6 mil e R \$3,275 mil. A prefeitura já recebeu os projetos e decretou os terrenos área de especial interesse social, abrindo caminho para que sejam realizados pelo programa. 'Estes projetos somam-se a outros três, já licenciados pelo município. Estamos avançando nesta questão', frisou o prefeito, fazendo referência aos empreendimentos Cenário de Monet, Bosque de Montreal e Palmeiras do Prado, que receberam incentivos fiscais da prefeitura e garantirão a construção de 8I4 novas unidades habitacionais na região de Correas”. (Portal Acontece Petrópolis, 3 de novembro de 20r5).

I3. “ Tramita na Câmara há pouco mais de Is dias um projeto de lei na Câmara para desafetaçáo de um terreno destinado ao Minha Casa, Minha Vida (MCMV) faixa I. O objetivo é passar uma área no Caititu para a faixa 2 do programa de construção moradias populares. O motivo é que as obras não tiveram início mesmo após dois anos após a desapropriaçáo do local.” (Barrosozo de novembro de 2015). 
primeiro distrito. Portanto, o PLHIS de Petrópolis dispóe que o déficit habitacional em assentamentos precários no primeiro distrito é de 2.994 moradias. Além disso, estabelece uma contrapartida de $362.625 \mathrm{~m}^{2}$ em terra urbana para resolver a demanda de domicílios nos assentamentos dessa área (Petrópolis, 20I2, pp. I44-45 e I53).

A listagem apresentada pelo PLHIS indica 22 terrenos, distribuídos em todo o município, adaptáveis ao perfil do mercado com seus grandes conjuntos habitacionais. Entre esses terrenos, dez ${ }^{14}$ estáo localizados no Primeiro Distrito, medindo o total de $186.000 \mathrm{~m}^{2}$. Sendo assim, faltam $192.625 \mathrm{~m}^{2}$ de terra urbana para zerar o déficit habitacional de 2.994 moradias em assentamentos precários localizados no primeiro distrito. Cabe lembrar que o déficit real de moradias nos assentamentos precários do Primeiro Distrito é superior ao apresentado pelo PLHIS quando consideradas as residências em situação de risco naquela área.

Tabela 3 - Déficit habitacional e demanda de terras no Primeiro Distrito

\begin{tabular}{ll}
\hline Déficit assentamentos precários & 2.994 \\
\hline Moradias em situação de risco & 7.076 \\
\hline Demanda de terras p/ assentamentos prec. & $362.625 \mathrm{~m}^{2}$ \\
\hline Disponibilidade de terras p/ assent. prec. & $186.000 \mathrm{~m}^{2}$ \\
\hline Carência de terras p/ assentamentos prec. & $192.625 \mathrm{~m}^{2}$ \\
\hline
\end{tabular}

Fonte: PLHIS. 2012.

Diante desse quadro, nota-se a imprescindibilidade de o poder municipal selecionar terra urbana apta a compor a sua política habitacional, o que leva ao dever de conhecer a totalidade do seu tecido urbano e incluir os imóveis ociosos como instrumentos de gestão urbana.

A partir desse contexto, a pesquisa de campo procurou identificar vazios urbanos classificados como terrenos vagos. A opçáo por essa categoria de imóvel ocioso explica-se pela dificuldade em identificar e comprovar, documental-

I4. Rua João Xavier, IOI5, bairro Duarte da Silveira (Io.0oom²); Rua Ângelo João Brandt, Quarteirão Italiano (48.00om²); Estrada do Caititu/Vale dos Esquilos, bairro Retiro (40.00om²); Pista de Esqui, bairro Floresta $\left(\mathrm{I} 5.000 \mathrm{~m}^{2}\right)$; Estrada Independência, clínica Pedras Brancas (25.00om²); Rua Vassouras, quadra 83, bairro Quitandinha (6.ooom²); Rua Quissamã, s/n, depósito da Seobras, bairro Quissamã $\left(6.000 \mathrm{~m}^{2}\right)$; Rua Quissamã, floricultura, bairro Quissamã $\left(8.000 \mathrm{~m}^{2}\right)$; Estrada Almeida Amado, bairro Caxambú (20.00om²); Alberto de Oliveira, bairro Mosela $\left(8.00 \mathrm{~m}^{2}\right.$ ) (PLHIS do município de Petrópolis, 20I2, p. I54). 
mente, os imóveis edificados, mas desocupados e aqueles subutilizados, o que exigiria a máquina do poder público como elemento de apoio. Além disso, a abrangência da pesquisa tornar-se-ia de tal forma complexa que ultrapassaria os limites possíveis a uma investigação acadêmica.

A pesquisa foi realizada nos bairros Quitandinha, Bingen e Duarte da Silveira por se situarem no Primeiro Distrito de Petrópolis onde há a maior concentração demográfica, circulação de riquezas e demandas de trabalho do município, e também por localizarem-se em áreas centrais da cidade dotadas com equipamentos públicos, infraestrutura e serviços básicos à população.

\subsection{Metodologia da pesquisa de campo}

O trabalho de campo se iniciou nas ruas dos bairros selecionados a partir da identificação visual de terrenos vagos. Constatando-se tal ociosidade, passava-se a anotação do número, lote ou quadra do imóvel se existisse e, ainda, de seus respectivos confrontantes para servir como material inicial à coleta de dados, e posteriormente como referência à localização dos imóveis nos arquivos municipais.

Após a seleção in loco, foi realizada uma busca nos arquivos dos órgãos públicos a fim de encontrar registros que confirmem a ociosidade antes identificada. Os documentos examinados fazem parte dos arquivos municipais da Secretaria de Fazenda, do Cadastro Imobiliário e da Assessoria de Cadastro e Edificação (ACADE), e consubstanciam-se em desenhos isolados dos locais pesquisados (croquis), mapa da Companhia Terrenos Quitandinha S.A., formulários de cadastro e plantas de situação.

Após muita pesquisa, foram localizados os imóveis vagos nos arquivos além de outros encontrados nos próprios registros municipais. A partir da identificação dos terrenos dentro dos arquivos foi possível levantar o espelho do IPTU de cada um deles, contendo a informaçáo da metragem e de que são terrenos sem uso no solo urbano. Dessa forma, foi confrontada a realidade fática com os registros da prefeitura.

No decorrer da pesquisa, foi observada a precariedade do cadastro municipal que opera com arquivos físicos compostos por formulários e desenhos antigos e amarelados cuja atualização é igualmente precária. Muitas áreas da cidade não possuem mapas de identificação territorial com lotes e quadras definidas a fim de facilitar a administração e fiscalização do solo urbano. $\mathrm{Na}$ 
realidade, apenas o bairro Quitandinha possui um mapeamento definido do seu solo com o respectivo plano geral de loteamento, elaborado em I950, pela Companhia Terrenos Quitandinha S.A.

Entre os imóveis que compóem o tecido urbano do Primeiro Distrito, foram catalogados 63 terrenos vagos ao todo. Destes, 39 estão localizados no bairro Quitandinha e 24 nos bairros Duarte da Silveira e Bingen. Esses terrenos somam a metragem de $216.782,352 \mathrm{~m}^{2}$, representando $60 \%$ dos $362.625 \mathrm{~m}^{2}$ de terra urbana necessária para eliminar o déficit habitacional dos assentamentos precários do primeiro distrito, de acordo com o PLHIS do município.

Tabela 4 - Distribuição e metragem dos imóveis vagos nos bairros pesquisados

\begin{tabular}{lll} 
BAIRRO & No DE TERRENOS & METRAGEM \\
\hline Quitandinha & 39 & $43.676 \mathrm{~m}^{2}$ \\
\hline Duarte da Silveira/Bingen & 24 & $173.106,352 \mathrm{~m}^{2}$ \\
\hline TOTAL & 63 & $216.782,352 \mathrm{~m}^{2}$ \\
\hline
\end{tabular}

Fonte: pesquisa de campo e Prefeitura Municipal de Petrópolis.

Dos terrenos pesquisados, constata-se que 3I deles estão com o IPTU em atraso há mais de três anos. Além disso, foi detectado que dois imóveis inicialmente considerados como vagos são, na realidade, áreas industriais que possuem grandes terrenos subutilizados. Essa realidade foi constatada após a coleta de dados nos registros do cadastro imobiliário. Além dessas, foi identificada uma área utilizada para estacionar poucos carros, que também poderia ser classificada como subutilizada, localizada ao lado de um terreno vago, o que permitiria um planejamento em conjunto para os dois terrenos.

Cabe acrescentar que vários lotes identificados na pesquisa são confrontantes uns dos outros, o que significaria a existência de grandes terrenos disponíveis, o que muito contribuiria para o plano habitacional da gestão municipal.

Tabela 5 - Identificação e metragem de terrenos subutilizados

\begin{tabular}{llll} 
BAIRRO & No DE TERRENOS & METRAGEM & EDIFICAÇÃO \\
\hline Quitandinha & OI & $566 \mathrm{~m}^{2}$ & $\mathrm{I} 79,00 \mathrm{~m}^{2}$ \\
\hline Duarte da Silveira/ & O2 & $2 \mathrm{I} .873,726 \mathrm{~m}^{2}$ & $2.506 \mathrm{~m}^{2}$ \\
Bingen & & $16.490 \mathrm{~m}^{2}$ & $809 \mathrm{~m}^{2}$ \\
\hline TOTAL & $\mathrm{O} 3$ & $38.363,726 \mathrm{~m}^{2}$ & $3.315 \mathrm{~m}^{2}$ \\
\hline
\end{tabular}

Fonte: pesquisa de campo e Prefeitura Municipal de Petrópolis. 
Observa-se, pelos dados apresentados, que o rastreamento de imóveis vagos representa a maior parte da terra urbana necessária para a eliminação do seu déficit habitacional em assentamentos precários em apenas três bairros do Primeiro Distrito do município. Isso leva à indagação de quantos imóveis vagos, não utilizados e subutilizados existem na área urbana de toda a cidade. Um cadastro territorial atualizado certamente poderia constituir-se em um instrumento que potencializaria a gestâo social da valorização fundiária que visasse à moradia social como vetor principal.

\section{Conclusóes}

Um estudo preliminar de campo, sem contar com mais recursos do que o empenho acadêmico, indicou a existência de terras urbanas dotadas de adequada infraestrutura urbana, mas que estão ociosas, em flagrante desrespeito à Constituição Federal que determina (no art. $5^{\circ}$, inciso XXIII, e art. I70, inciso III) que a propriedade deve cumprir sua função social.

O Programa Minha Casa, Minha Vida tem a importante virtude de mobilizar valores significativos e inéditos para subsidiar a moradia social. Apresenta, contudo, muitas deficiências, algumas das quais foram destacadas nesse texto. Entretanto, nunca é demais lembrar que se trata de um programa formulado e financiado pelo governo federal. Os governos estaduais e, principalmente, os municipais precisam atuar na política habitacional, que, como as demais políticas sociais, são de responsabilidade das três esferas de governo.

A política urbana, no entanto, está expressamente normatizada como de competência municipal. Considerando que a moradia é parte da política urbana, os municípios deveriam atuar no sentido de conciliar o programa federal às particularidades do seu território. Não deveriam recepcionar o PMCMV como se sua atuação se restringisse apenas a aderir ao programa.

O estudo ora apresentado sugere a necessidade de atuação mais propositiva dos governos municipais, caso sejam exploradas as possibilidades que um cadastro territorial atualizado lhes ofereceriam. Afinal, identificamos terrenos ociosos, correspondendo a um total de aproximadamente $60 \%$ de solo urbano necessário para enfrentar o déficit habitacional naquela localidade. 


\section{Referências}

BARROSO, Romulo. "Vereadores discordam sobre Minha Casa Minha Vida”. Jornal Diário de Petrópolis. Petrópolis, 30 nov. 20I5. Disponível em: http://diariodepetropolis.com.br/integra/ vereadores-discordam-sobre-minha-casa-minha-vida-76728. Acesso em: or dez. 2015.

BONDUKI, Nabil. Habitar São Paulo: reflexóes sobre a gestão urbana. São Paulo: Estação Liberdade, 2000.

"Do projeto Moradia ao programa Minha Casa Minha Vida”. TD: Teoria e Debate, v. 82, p. 8-I4, São Paulo, maio 2009.

BRASIL. Constituição brasileira, I988. Texto constitucional de 5 de outubro de I988. Brasília: Senado Federal, Centro Gráfico.

Portaria Ministerial n. ${ }^{\circ}$ 5II, de 07 de dezembro de 2009. Determina diretrizes para a criação, instituição e atualização do Cadastro Territorial Multifinalitário (CTM) nos municípios brasileiros. Diário Oficial da União, 08 dez. 2009.

CANEJO, Andressa. "No de vítimas em tragédia no RJ pode ser Io vezes maior, dizem entidades”. Portal GI, Io ago. 20I5. Disponível em: http://gi.globo.com/rj/regiao-serrana/noticia/20I5/o8/entidades-apontam-subnotificacao- de-vitimas-da-tragedia-de-20II- na-serra.html. Acesso em:

CARDOSO, A. Lúcio e ARAGÃO, T. Amorim. "Do fim do BNH ao Programa Minha Casa, Minha Vida: 25 anos da política habitacional no Brasil”. In (org.). O programa Minha Casa Minha Vida e seus efeitos territoriais. Rio de Janeiro: Letra Capital, 20I3, pp. $17-65$.

EQUIPE ACONTECE PETRÓPOLIS. "Bingen, Pedro do Rio e Morin receberão empreendimentos do Minha Casa Minha Vida”. Portal Acontece Petrópolis. Petrópolis, 03 nov. 2015. Disponível em: http://www.aconteceempetropolis.com.br/2015/11/03/bingen- pedro-do-rio-e-morin-receberao-empreendimentos-do-minha- casa-minha-vida/.

FRAJNDLICH, Rafael Urano. "Jirau Arquitetura desenha nova proposta de habitação social para o Programa Minha Casa Minha Vida em Caruaru, PE”. AU - Arquitetura e Urbanismo, ano 27, n. 224, 20I2. Disponível em: http://au.pini.com.br/arquitetura- urbanismo/224/modernas-referencias-bairro-habitacional- desenhado-pela-jirau-arquitetura-em-273I87 -I.aspx. Acesso em: I4 set. 20I4.

HAUBRICH, Gabriela. "Falta oferta de moradias populares em Petrópolis. Verbas do 'Minha Casa Minha Vida’ não atraem empreiteiras devido ao alto custo da construção na cidade”. Jornal Diário de Petrópolis, Petrópolis, 15 jun. 2015. Disponível em: http://diariodepetropolis.com.br/Integra/falta-oferta-de-moradias-populares-em-petropolis-66954. 
PETRÓPOLIS. PLHIS - Plano Local de Habitação de Interesse Social. Petrópolis: SEHAB, 2012.

Prefeitura Municipal. "Bomtempo vistoria andamento das obras do novo Conjunto Habitacional do Vicenzo Rivetti". Petrópolis, I8 mai. 20I4. Disponível em: http://www. petropolis.rj.gov.br/pmp/index.php/ imprensa/noticias/item/2247- bomtempo-vistoria-andamento-das-obras-do-novo-conjunto-habitacional- do-vicenzo-rivetti.html. Acesso em: 17 jun. 2014.

. Prefeitura Municipal. "Prefeito vistoria obra de pavimentação da Estrada do Caititu”. Petrópolis, I4 abr. 20I4. Disponível em: http:// petropolisnews.com.br/?p=3626.

RITTO, Cecília. "Petrópolis se desmancha: com obras paradas, município tem 27 mortos e mais 366 famílias desabrigadas". Veja. Com, Rio de Janeiro, I9 mar. 2013. Disponível em: http://veja.abril.com.br/brasil/petropolis- se-desmancha-com-obras-paradas- municipio-tem-27-mortos-e-mais- 366-familias-desabrigadas/.

ROLNIK, Raquel. "Arquitetura: direito de todos". Jornal Folha de S. Paulo, São Paulo, os out. 2015. Disponível em: http://wwwi.folha.uol.com.br/colunas/raquelrolnik/2015/ro/ I690I64-arquitetura-direito-de-todos.shtml. Acesso em: 22 nov. 2015.

SHIMBO, Lúcia Zanin. Habitação social, habitação de mercado: a confluência entre Estado, empresas construtoras e capital financeiro (tese). USP. Disponível em: http://www.teses.usp.br/ teses/disponiveis/I8/I8I42/tde-040820IO-IOOI37/. Acesso em: Io jun. 2014. 